\title{
THE PRACTICE AND AWARENESS OF GENDER RESPONSIVE INSTRUCTIONAL APPROACHES DURING COLLEGE OF EDUCATION CHEMISTRY LESSONS - A CASE STUDY
}

\author{
Solomon Boachie', \\ Francis Quansah", \\ Emmanuel K. Oppong ${ }^{3 i}$ \\ ${ }^{1}$ Department of Science, \\ St. Ambrose College of Education, \\ Dormaa-Akwamu, Ghana \\ ${ }^{2}$ Department of Science, \\ Foso College of Education, \\ Assin Foso, Ghana \\ ${ }^{3}$ Department of Chemistry Education, \\ University of Education, \\ Winneba, Ghana
}

\begin{abstract}
:
This study examined the awareness level of chemistry tutors on gender responsive instructional approaches, and the extent to which the tutors apply gender responsive teaching practices in chemistry lessons at St. Ambrose College of Education in Ghana. A case study design was adopted for this study. Non-probability sampling techniques were used for the study. Specifically, the quota sampling and the purposive sampling procedure were adopted for the study. Purposive sampling procedure was used to select two chemistry tutors and a vice principal of the college. The student population was 72 . Quota sampling was used to select $20 \%$ of 38 females and $20 \%$ of 34 males for the study. The sample for the study was 18. An interview guide and structured observation checklists were the main instruments used for the data collection. To determine the reliability of the interview questions and observation guide for both students and tutors, pilot test was conducted at Foso College of Education. Manual analysis was used to analyse the data. Thematic analysis was used for the analysis. The findings from the study revealed that chemistry tutors have adequate knowledge in gender instructional approaches because of regular professional development sessions. The vice principal, chemistry tutors and students identified the lack of chemistry laboratory, unsuitable classroom set up and desks and the weak guidance and counselling unit as the major hindrances to effective implementation of gender responsive instructional approaches during chemistry lessons. It was recommended that ergonometric desk, guidance and
\end{abstract}

'Correspondence: email emmakyameoppong@yahoo.com 
counselling unit, adequate teaching learning resources and chemistry laboratories should be provided to enhance effective implementation of gender pedagogy during chemistry lessons.

Keywords: practice, awareness, gender responsive, instructional approaches, chemistry

\section{Introduction}

The sustainable development goal five (SDG-5) demands equal access to education without any form of intimidation, sexual harassment and discrimination (UNESCO, 2012). Several studies have confirmed that gender responsive pedagogy, defined by Makoye (2005) as making the teaching and learning processes respond to the specific needs of girls and boys is essential to the achievement of quality learning in the 21st century. This includes both males' and females' successful transition to and performance in secondary school and beyond (Sperling \& Winthrop, 2016). However, despite the importance of gender-balanced education, traditional approaches to pedagogy have been criticised for not acknowledging differences among students, including differences based on gender and cultural backgrounds (Andersson, 2016). Schools being social sites where the socialisation process is reinforced, it is necessary that the social, physical and academic environments are set up to reinforce the construction of masculine and feminine set-up starting from early ages. There is a significant body of evidence demonstrating that addressing inequalities in girls' education is an effective strategy for breaking the cycle of intergenerational poverty and for lifting girls and their families out of positions of marginalisation (GES, 2018). In Ghana, the importance of improving girls' access, retention and transition through the education system, from kindergarten through to tertiary education is widely acknowledged (MoE, 2018). As such, there has been a growing interest in and efforts at addressing gender related barriers in the education system. One major hindrance related to girls' access to education involves issues surrounding girls' school enrolment (entry), survival and completion (MoE, 2018). The teacher has been identified as a critical factor in sustaining grade survival and completion of the girls child in schools. It has been argued that the teacher's adoption of gender-responsive pedagogy is one way to ensure grade survival and completion for both boys and girls (MoE, 2018; GES, 2018). The school is particularly expected to create an enabling learning environment for girls. The use of gender sensitive pedagogy is therefore critical if the dominant gender bias within a patriarchal system is to be challenged.

The problem in this study focused on the gender responsive instructional approaches during chemistry lessons at St. Ambrose College of Education located at Dormaa Akwamu in the Bono Region of Ghana. In Ghana and beyond, there have been studies that indicate the existence of teachers who overlook at issues regarding gender responsive pedagogy during their lesson deliveries. Girls face greater constraints on pursuing their studies due to household demands on their labour, threats to their 
physical safety, lack of necessary sanitation facilities in schools and societal beliefs that privilege investments in boys' education (Kreitz-Sandberg, 2016). This study examined the awareness level of chemistry tutors on gender responsive instructional approaches, and the extent to which the tutors apply gender responsive teaching practices in chemistry lessons at St. Ambrose College of Education in Ghana.

Research Question: What specific gender responsive approaches do the tutors utilise during chemistry lessons?

\section{Literature Review}

According to Lindsey (2015), gender refers to those social, cultural, and psychological traits linked to the males and females through particular social contexts, whilst sex refers to the biological characteristics distinguishing male and female. This definition emphasises male and female differences in chromosomes, anatomy, hormones, reproductive systems, and other physiological components. Sex makes us male or female, and ascribed status because a person is born with it. On the other hand, gender makes one masculine or feminine, and it is also achieved status because it can be learned. Gender is not a personal trait but one that develops through the process of interaction within the environment, and educational institutions have become important arenas for the construction and reconstruction of these norms that shape the perceptions of gender. Observations of classroom practices show that teaching and learning is largely gender biased. Many teachers apply teaching methodologies that do not give girls and boys equal opportunities to participate. They also use teaching and learning materials that perpetuate gender stereotypes.

In many schools, the implementation of gender responsive pedagogy has been challenging. There are still numerous stereotypes associated with how girls are taught in the classroom, where teachers traditionally have lower expectations and biases against female students (Nabbuye, 2018). It also translates into how girls and boys are raised and treated at home and in the professional world. Researchers have identified several factors or reasons accounting for the low application of gender-responsive pedagogy in schools. For instance, according to Nabbuye (2018), one of such reasons is the fact that teachers' gender bias has been overlooked in most schools. It is important to note that teachers' perception of their students' abilities can sometimes affect how they teach, assign roles, and engage with their students. Some of these challenges could be solved by using gender- responsive pedagogy as a means to get teachers to check their own gender biases and perceptions. Once this is achieved, teachers can actively engage all students to improve academically and boost confidence. Teachers view girls through stereotypescharacterising girls as struggling to actively engage in their studies even though they are attending school.

Consequently, there is an urgent need to introduce gender responsive pedagogy in science education, especially chemistry lessons. Pedagogy as a concept embraces virtually all teaching and learning processes. Within the context of classroom settings, 
pedagogy is a term that includes what is taught, how teaching takes place and how what is taught is learnt. Gender responsive pedagogy refers to teaching and learning processes that pay attention to the specific learning needs of girls and boys. Gender responsive pedagogy calls for teachers to take an all-encompassing gender approach in the processes of lesson planning, teaching, classroom management and performance evaluation (Mlama, Dioum, Makoye, Murage, Wagah \& Washika, 2005). Researchers have confirmed that if teachers use gender-responsive pedagogy effectively, it can result in several benefits that can lead to empowerment and quality education outcomes - for both boys and girls (Kahamba, Massawe \& Kira, 2017). For instance, it can help prevent gender stereotyping. Gender-responsive teachers using gender-responsive pedagogy to support children is questioning traditional gender roles and attitudes (Kahamba et al., 2017). With gender-responsive pedagogy, students are encouraged to engage in learning equally and actively, which improves performance and attainment of goal and ability to teach themselves (Nabbuye, 2018). They engage and equally participate in group discussions, debates, field study trips, project-based learning, and presentations. A genderresponsive program by Forum for African Women Educationalists (FAWE) implemented in Malawi, Tanzania, Ethiopia, Gambia, and Zambia led to a change in teachers' attitudes and practices, increased girls' access to and participation in school, enrolment, and enhanced retention (Nabbuye, 2018).

This study examined the awareness level of chemistry instructors on gender responsive pedagogy, and the extent to which the instructors apply gender responsive instructional approaches during College of Education chemistry lessons. The theoretical frame work of this study was rooted in social constructivism. Social Constructivist Theory was propounded by Lev Vygotsky and it emphasise the importance of culture and context in understanding what occurs in society and constructing knowledge based on this understanding (Mckinley, 2015). Lev Vygotsky challenged the views of Jean Piaget that cognitive development is as an individual process, rather than a collaborative effort. Although Vygotsky's ideas acknowledged individual psychology in cognitive development, he shifted the focus to external forces that were entwined with the internal world in which Piaget centered his theories (Jones \& Araje, 2002). 
Figure 1: Social Constructivist Theory

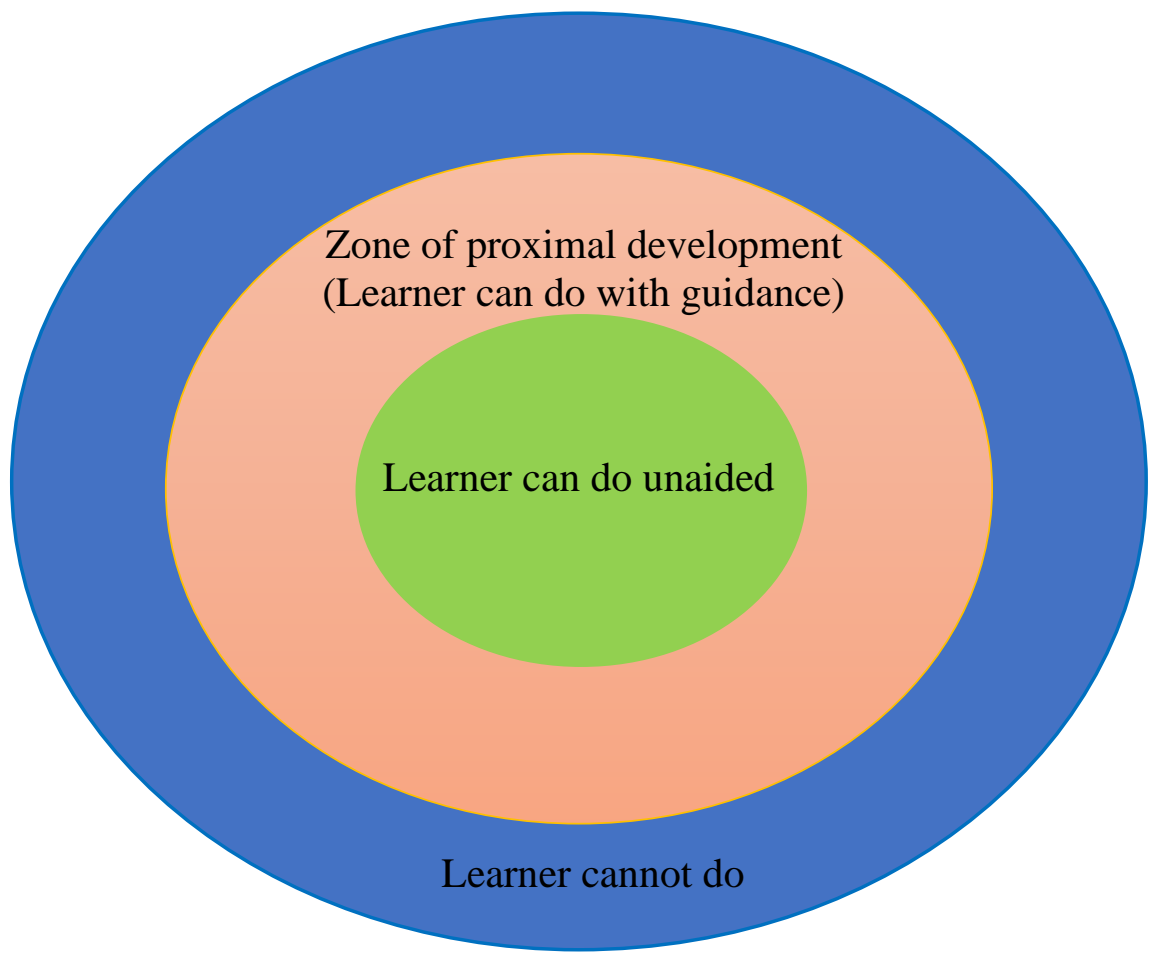

Source: Jones and Araje (2002)

According to Jones and Araje (2002), learning at the individual process stage though effective, cannot achieve much compared to learning in a collaborative manner. Rather, interaction with peers is rather a successful means of developing skills and strategies. The Zone of Proximal Development (ZPD) refers to 'the distance between the actual developmental level as determined by independent problem solving and the level of potential development as determined through problem solving under adult guidance or in collaboration with more capable peers. In the ZPD, a teacher and a learner work together on a task that the learner could not perform independently because of the difficulty level. Also, it reflects the idea of collective activity, where those who know more or are more skilled share that knowledge and skill to accomplish a task with those who know less. A good deal of guided participation is required when working in the ZPD and learners bring their own understandings to social interactions and construct meanings by integrating those understandings with their experiences in the context.

Social constructivism is based on specific assumptions about reality, knowledge, and learning (Kalina, 2009). Social Level is between people which is called interpsychological and then individual level which is inside the child - called intrapsychological. In inter-psychological level, child acquires knowledge through contacts and interactions with people and then later the child assimilates and internalizes this knowledge adding own personal value to it in intra-psychological level. 
Figure 2: Social Constructivists Theory

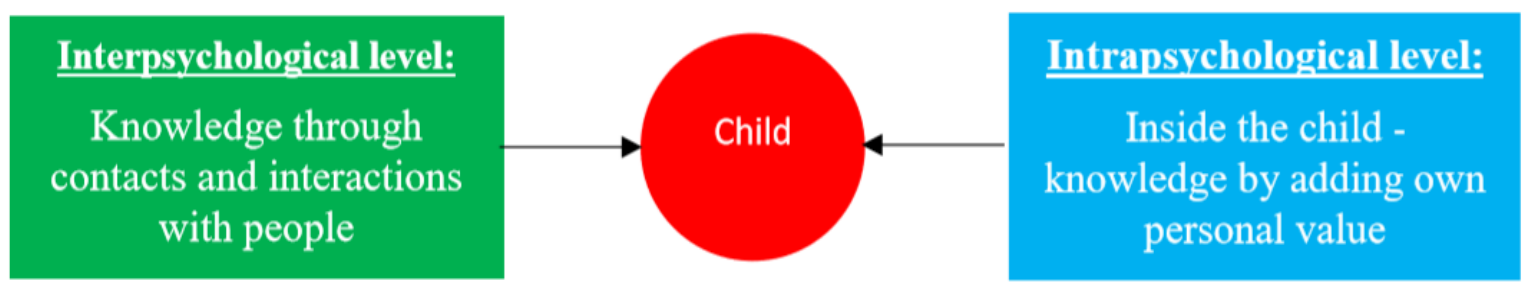

Source: Jones and Araje (2002)

The More Knowledgeable Other (MKO) refers to anyone who has a better understanding or a higher ability level than the learner, with respect to a particular task, process, or concept. The MKO is normally thought of as being a teacher, coach, or older adult, but the MKO could also be peers, a younger person, or even computers.

To understand and apply models of instruction that are rooted in the perspectives of social constructivists, it is important to know the premises that underlie them.

- Reality: Social constructivists believe that reality is constructed through human activity. Members of a society together invent the properties of the world. For the social constructivist, reality cannot be discovered: it does not exist prior to its social invention (Kalina, 2009).

- Knowledge: To social constructivists, knowledge is also a human product, and is socially and culturally constructed. Individuals create meaning through their interactions with each other and with the environment they live in.

- Learning: Social constructivists view learning as a social process. It does not take place only within an individual, nor is it a passive development of behaviours that are shaped by external forces. Meaningful learning occurs when individuals are engaged in social activities.

\section{Educational Implications of Social Constructivists Theory}

In education, the theory argues that children and adults are both active agents in the process of child's development (Kalina, 2009). The implication of this theory to teaching means that both the teacher and a student are seen as active agents in children's learning. The teacher's intervention in children's learning is necessary, but it is the quality of the teacher-learner interaction, which is seen as crucial in that learning (Jones \& Araje, 2002).

- Reciprocal teaching: It involves interactive dialogues between teacher and small group of students. At first, the teacher models the activities. After that teacher and students take turns being the teacher (Jones \& Araje, 2002).

- Peer collaboration: The shared social interactions when peers work on tasks cooperatively serve an instructional function. This method is mainly used in learning science, mathematics, and language arts which attests to the recognized impact of the social environment during learning (Jones \& Araje, 2002). 
- Apprenticeship Programs: This occur in cultural institutions like schools and agencies which helps in transforming learners' cognitive development. On the job, apprentices operate within a ZPD as mainly their works depend on tasks beyond their capabilities. Apprentices develop a shared understanding of important processes by working with experts and integrate this with their current understandings (Jones \& Araje, 2002).

Kahamba et al (2017), conducted a study in Tanzania which is among Sub-Saharan African countries where teachers are conditioned by male-dominated values in their communities. The findings revealed the degree of gender sensitive pedagogical teaching practices to be very low. Abraha, et al., (2019), conducted a mixed methods study in Ethiopia. The study examined the general secondary school (GSS) science teachers' gender responsive pedagogy (GRP) implementation status. The analysed data noted that GSS science teachers of the North Wollo Zone had facilitated Gender Responsive Pedagogy fairly. However, in the Ghanaian context, particularly at the level of the colleges of education, there is no study which has examined the practice and awareness in gender pedagogy during college of education chemistry lessons.

\section{Methodology}

\subsection{Research Design}

The research approach used was the qualitative and aimed at understanding some aspects of social life through the generation of words rather than numbers as data for analysis (Bryman, 2012; Chambliss \& Schutt, 2009). The qualitative approach refers to any kind of research that produces findings not arrived at by means of statistical procedure or other means of quantification. In other words, qualitative research involves the narrative description of events and phenomenon within their natural settings without the use of quantitative measures. It is a naturalistic inquiry, the use of non-interfering data collection strategies to discover the natural flow of events and processes and how participants interpret them. In general, qualitative research shares the theoretical assumptions of the interpretative paradigm, which is based on the notion that social reality is created and sustained through the subjective experience of people involved in communication (Bryman, 2008). After reviewing various educational research designs, the researchers found case study design as the most suitable approach especially as the researchers seeks to establish in-depth knowledge on practices and awareness of gender responsive pedagogy in the teaching and learning of chemistry. A Case study is generally accepted as flexible and adoptable to processes, people and context and provides some of the most useful methods in educational research. Wahyuni (2012), identified three main types of case study designs as Intrinsic, Instrumental and Collective case studies. Intrinsic case studies are suitable when the researcher wants to understand a particular case in question; Instrumental case studies are suitable when the researcher seeks to examine a particular case in order to gain insights into a theory or an issue; and Collective case studies are best when the researcher wants to conduct groups of individual studies 
that are undertaken to gain a fuller picture (Wahyuni, 2012). This study aligns with the intrinsic case study design. Case study design has been criticised for being weak in terms of generalisability and validity (Wahyuni, 2012). This weakness is however addressed through specification of what the case is and what the unit of analysis is. As noted earlier, the case for this study is investigating the practice and awareness of gender responsive instructional approaches during College of Education chemistry lessons. The case study is a strategy for conducting research, which involves an empirical investigation of a particular phenomenon within its real-life context using multiple sources of evidence. According to Creswell, 2012 case study involves an in-depth exploration of bounded process or individuals' system based on extensive data collection (Yin, 2009). Also, a case study as a bound system means that the study is located within a geographical boundary, which is limited by number of informants providing the data for the study (Yin, 2009). In this study the case under examination is St. Ambrose College of Education, DormaaAkwamu in the Bono Region of Ghana where the second author teaches. The reason for this, is to get a deeper understanding of the phenomenon under investigation. Therefore, the researchers were interested in information-rich case in order to come out with better understanding of the phenomena under investigation. In this study 18 research participants were selected for the study.

Table 1: Number of Research Participants for the Study

\begin{tabular}{|l|c|c|c|}
\hline Category & Male & Female & Total \\
\hline Vice principal & 1 & - & 1 \\
\hline Chemistry tutors & 1 & 1 & 2 \\
\hline Students & 7 & 8 & 15 \\
\hline Total & $\mathbf{9}$ & $\mathbf{9}$ & $\mathbf{1 8}$ \\
\hline
\end{tabular}

The researchers used interviews and observation schedule to collect data for the study. This was due to ease of administration, ease of eliciting response, validity and reliability of the instrument and timing as the qualitative nature of the study informed the selection of the data gathering techniques.

\subsection{Sample and Sampling Procedure}

The sample for this study was taken from level 200 Bachelor of Education Primary education students in St. Ambrose College of Education students at Dormaa-Akwamu. The researchers chose to conduct the study with level 200-year students because the chemistry tutors and their student teachers have attended gender pedagogy workshops in the previous year. Chemistry tutors were therefore expected to demonstrate knowledge and understanding about gender pedagogy in their chemistry lessons. According to Sidhu (2003), sampling is the process of selecting a representative unit from a population

Non- probability sampling techniques were used for the study. Specifically, the quota sampling and purposive sampling procedures were adopted. According to Gaganpreet (2017), the use of quota sampling helps researchers to make meaningful 
comparison from groups within a targeted population. Therefore, this sampling procedure became the most appropriate as it offered the opportunity to select proportional representatives of both males and females in the college. The purposive sampling procedure was applied to the chemistry tutors and the vice-principal of the college. These key individuals were selected because of their level of knowledge about the area under investigation.

This offered the researchers the opportunity to select proportional representatives of both males and females in the institution. The students' population was 72 , therefore $20 \%$ of 38 females and $20 \%$ of 34 males were conveniently sampled for the study. According to (Dörnyei, 2007), Convenience sampling is a kind of non-probability or nonrandom sampling in which members of the target population are selected for the purpose of the study if they met certain practical criteria, such as geographical proximity, availability at a certain time, easy of accessibility, or the willingness to volunteer. The student teachers were in second year (level 200) at the time of the study.

\subsection{Research Instrument}

The main research instruments used were semi-structured interview and observation schedule which were constructed and structured by the first and second authors. The semi-structured interviews were supplemented with observations for the purpose of triangulation. An observation is an important supplementary technique for research that is based on interviews, where the researcher makes notes on observable behaviours of participants at the research site (Creswell, 2012, p.190). The critical "watch-on" during the instructional process, helped the researchers to identify which questions needed further exploration and when it was helpful to encourage the participant or when to abandon a line of questioning. Carter (2007) defined interview as a researcher participant conversation that aims at helping the former gather research-relevant information. Interview is regarded as one of the most efficient qualitative research data collection tools as it brings out people's daily experiences and their inner perceptions, attitudes, and feelings of reality. Interview is also viewed as one of the main data collection tools in qualitative research and a very good way of assessing people's daily experiences and their inner perceptions, attitudes, and feelings of reality. To ensure the face and content validity of the instruments, the instruments were given to the first author, who was the second author's lecturer in the Department of Science Education, University of Education, Winneba, to determine the content validity, identify any ambiguities and also made the necessary clarifications to items. This was to ensure whether the items reflected the intent of the instruments. To ensure the reliability of the research instruments, the classroom teaching observation was carried out on three different occasions during chemistry lessions. The reliability of the interview questions for both students and teachers were pilot tested in Foso College of Education by the third author, who was also a tutor in the College. 


\subsection{Data Collection and Analysis}

Before the data collection began, the first and second authors interacted with the students and explain to them the rationale and the purpose for the study in order to solicit their maximum co-operation so that the objectives of the study could be achieved. The classroom teaching observations was also scheduled with the chemistry tutors before observation was made. The researchers scheduled convenient time for research participants for the interview. The semi-structured interview schedule called pre-service students interview schedule (PSIS) was developed by the first and second authors and used to collect data from the participants. The PSIS which took the form of face-to- face free and friendly interaction with participants sought to elicit participants views on how gender responsive instructional approaches are practised during chemistry lessons. This approach helped the researchers to talk to them, to listen to them and gain access to their real-classroom teaching experiences as well as detail information on the nature of gender responsive instructional approaches practised during chemistry lessons. Each interview schedule last between 15 and 20 minutes. Between four and five participants were interviewed within a day for a chemistry lesson that lasted for two hours in a week for four weeks. These interviews were conducted for the vice-principal, chemistry tutors and the students' teachers. In all eighteen individuals were interviewed; fifteen students, two chemistry tutors and the only one vice principal. The interviews were audiotape recorded for each of the eighteen research participants and played several times for transcription. Transcriptions of recorded interviews were done by listening to the tape conversation repeated and carefully writing them down with each interviewee. Observation instrument was also used to collect data. The data were analysed manually. The researchers did several readings of field notes, interviews and comments and reexamined the categories, and then, allocated pseudonyms to each participant's responses to the interview questions, noting similarities and differences. Students were assigned pseudo name such as St1, St2, St3 up to St15. Tutors were assigned names such as Tutor $\mathrm{A}$ and Tutor B. The vice principal was named as Mr. P.

\section{Findings - On the Research Question}

"What specific gender responsive approaches do the tutors utilise during chemistry lessons?"

Responses from interviews from Tutors and students;

"I use participatory methods like class discussions and grouping with mixed ability which include both gender". (A)

"I avoid the use of pronouns like he or she that references to only one gender and try to mention students by their names". (B) 
"Our chemistry tutors utilise discussion and grouping work. During group presentation, females were given leader roles". (St 1)

"Our chemistry tutor "B", administer Teaching and Learning materials (TLM) to both males and females' students and assign equal responsibilities to both gender". (St. 3)

The interview was triangulated with classroom observation and the following findings were identified during observation schedules.

1) It was found that chemistry tutors in St. Ambrose College of Education used participatory methods of teaching such as group work, group projects and discussions that involved both sexes.

2) Chemistry tutors in St. Ambrose College of Education were consistently seen directing questions to both sexes by encouraging especially females to express their views. This was done with gender sensitivity in mind.

3) It was observed that the furniture or desk arrangements for the student teachers in St. Ambrose College of Education were not good for chemistry lessons and the writing boards were also fixed at the top conner of the wall.

4) It emerged from the observation and interview data that, language used by the chemistry tutors in St. Ambrose College of Education during classroom interaction were gender responsive as they treated both males and females equally and friendly.

\section{Discussion}

Regarding the research question "what specific gender responsive approaches tutors utilise during chemistry lessons?", the study's responses showed that chemistry tutors have fair idea about the utilisation of this approach during chemistry lessons. The outcome of this study on specific gender responsive approaches during chemistry lessons was confined to science student teachers during chemistry lessons in St. Ambrose College of Education, Ghana. Nevertheless, this study's results supported several other studies' results that had identified worked on specific gender responsive approaches which were effective at different institutional levels, different course areas, and different geographical locations in Ghana and beyond.

Ananga (2021) presented a paper on Gender Responsive Pedagogy for Teaching and Learning: The Practice in Ghana's Initial Teacher Education Programme and the paper reported that, there has been significant improvement in the use of gender responsive pedagogy in the areas of the core subjects (English, Mathematics and Science) from the teachers sampled. The paper concludes by highlighting the implications of the findings for policy adoption of gender-sensitive pedagogy in Ghana's initial teacher training programme.

In Tanzania, Kahamba et al. (2017) conducted a study. Their findings revealed the degree of gender sensitive pedagogical teaching practices to be very low. In Ethiopia, a 
similar study was conducted by Abraha, et al., (2019) the study concluded that teachers of the North Wollo Zone had facilitated Gender Responsive Pedagogy fairly.

As this study results are consistent with the results of the aforementioned studies in the area of specific gender responsive pedagogy teachers utilised during instructional deliveries at different setting, it suffices to say that, implementing gender responsive pedagogy is effective in teaching various subject disciplines irrespective of the level and geographical area. In the context of institutions in Ghana, specifically at the colleges of education level, the outcome of this study however, attests to the fact that teachers' perception of their students' abilities can sometimes affect how they teach, assign roles, and engage with their students. Some of such challenges could be resolved by using gender- responsive pedagogy as a means to get teachers to check their own gender biases and perceptions. Once this is achieved, science instructors generally and specifically chemistry tutors can actively engage students to improve academically and boost confidence. More attention should be given to the implementation of gender responsive instructional approaches in the teaching and learning of chemistry. This is because such gender responsive instructional approaches tend to empower and improve the quality of educational outcomes-for both boys and girls. Gender pedagogy implementation during teaching and learning also encourage students to engage in learning equally and actively, which enhances performance and attainment of SDG-5 and "boost" students' ability to teach themselves as this has yielded significant higher achievements as revealed in literature.

\section{Conclusion}

Establishing the Gender Responsive pedagogy (GRP) approaches chemistry tutors utilise during chemistry lessons was largely informed by the observation and interview done by the researchers. The subsequent paragraphs give a walk-through on GRP approaches chemistry tutors utilise during chemistry lessons observed by the researchers. Concerning lesson planning, the researchers observed that the chemistry tutors used participatory methods of teaching; such as group work, group projects and discussions that involved both sexes. The researchers observed chemistry tutors using these methods and students were seen interacting with the opposite sex smoothly. Such interactions appeared to be rooted in the college's culture.

Teaching and learning materials used for the chemistry lessons were fairly distributed among both males and females. This was reinforced by group works and presentations where both sexes, including females, were given leadership roles. Beyond this, no usage of negative expressions that demeans one gender was observed in the lesson.

Classrooms were set up in a fashion where both males and females were mixed evenly. Students abilities were observed to have been factored into the arrangement. However, there were few observed challenges; firstly, the desks and furniture were found not to be user friendly for chemistry lessons especially during group discussions and also 
the writing boards were fixed at one top conner of the wall. Such challenges were observed to posed some discomfort to students, especially females and hindered their full attention.

The implication of the outcome of this study is that science tutors generally and specifically chemistry tutors in the colleges of education in Ghana could consider using gender responsive instructional approaches as a cooperative learning strategy in the delivery of their science lessons since the gender responsive instructional approaches has stood the test of time as an effective teaching strategy for reducing school drop-out rate especially, among the females. Science student teachers could as well adopt gender responsive instructional approaches in their group studies as it has proven to be learnercentred teaching strategy, highly innovative in developing problem-solving skills and creativity among learners.

\section{Aknowledgement}

All authors participated equally in the research.

\section{Conflict of Interest Statement}

The authors declare no conflict of interest.

\section{About the Authors}

Solomon Boachie, MPhil. Science Education, Professional Science Educationist.

Francis Quansah, MPhil. Science Education, Professional Science Educationist.

Emmanuel Kyame Oppong (PhD), Natural Products, Dip. Education, Natural Product Chemist and Educationist.

\section{References}

Abraha, M., Dagnew, A., \& Seifu, A. (2019). Gender responsive pedagogy : Practices, challenges \& Opportunities - A case of secondary schools of North Wollo Zone, Ethiopia. Journal of education, society and behavioural science, 30(3), 1-17.

Ananga, E. (2021). Gender Responsive Pedagogy for Teaching and Learning: The Practice in Ghana's Initial Teacher Education Programme. Creative Education, 12, 848-864

Andersson, K. (2016). Chemistry for whom? Gender awareness in teaching and learning chemistry. Cultural Studies of Science Education. Springer Netherlands.

Bryman, A. (2008). Social research methods, (3rd). Oxford University Press.

Bryman, A. (2012). Social research methods (4ed). Oxford University Press.

Carter, S. M. (2007). Justifying Knowledge, Justifying Method, Taking Action: Epistemologies, Methodologies, and Methods in Qualitative Research. Qualitative health research, 17(10), 1316-1328.

Chambliss, D. F \& Schutt, R. K (2009). Making sense of the social world methods of investigation ( $3^{\text {rd }}$ ed). Pine Forge Press. SAGE Publications. 
Creswell, J. W. (2012). Qualitative, quantitative, and mixed methods approaches. research design (4th ed). Sage Publication Ltd.

Dörnyei, Z. (2007). Research methods in applied linguistics. New York: Oxford

GES (2018). The Gender Handbook for Teaching Practice Mentors: A Guide for Implementing

Gender Responsive Pedagogy, Policies and Practices during Teaching Practice. Accra: GES.

Jones, M., \& Araje, L. (2002). Vygotsky's social constructivists theory of learning. American communication journal, 5(3), 1-3.

Kahamba, J. S., Massawe, F. A., Kira, \& E. S. (2017). Awareness and practice of gender responsive pedagogy in higher learning institutions: The case of Sokoine University of Agriculture, Tanzania. Journal of education, humanities and sciences, $6(2), 1-16$.

Kalina, C. (2009). Cognitive and social constructivism: developing tools for an effective classroom. Education, 130(2), 241-250.

Kreitz-Sandberg, S. (2016). Improving pedagogical practices through gender inclusion: examples from university programmes for teachers in preschools and extended education. International journal for research on extended education, 4(2), 71-91.

Lindsey, L. L. (2015). Gender roles: A sociological perspective. Routledge.

Makoye, H. (2005). Gender responsive pedagogy (1st ed.). Nairobi, Kenya: Forum for African Women Educationalists (FAWE).

Mckinley, J. (2015). Critical Argument and writer identity: social constructivism as a theoretical framework for EFL academic writing. Critical Inquiry in Language Studies, 12(September), 184-207.

Mlama, P., M. Dioum, H. Makoye, L. Murage, M. Wagah, \& R. Washika (2005). Gender Responsive Pedagogy: A Teacher's Handbook. Nairobi: Forum for African Women Educationalists (FAWE).

MoE (2018). Education Strategic Plan 208-2030. Accra: Ministry of Education.

Nabbuye, H. (2018). Gender-sensitive pedagogy: The bridge to girls' quality education in Uganda. Kampala.

Sidhu, K. S. (2003). Methods of research in education. New Delhi: Sterling Publishers.

Sperling, G. \& Winthrop. R. (2016). What works in girls' education? Washington DC: Brookings Institution Press.

UNESCO. (2012). Education for sustainable development. Paris, France: UNESCO Education Sector. University Press.

Wahyuni, D. (2012). The research design maze: understanding paradigms, cases, methods and methodologies. JAMAR Research, 10 (1), 69-80.

Yin, R. K. (2009). Case study research design and methods ( $4^{\text {th }}$ ed). Sage. Publication, Inc. 
Authors will retain the copyright of their published articles agreeing that a Creative Commons Attribution 4.0 International License (CC BY 4.0) terms will be applied to their work. Under the terms of this license, no permission is required from the author(s) or publisher for members of the community to copy, distribute, transmit or adapt the article content, providing a proper, prominent and unambiguous attribution to the authors in a manner that makes clear that the materials are being reused under permission of a Creative Commons License. Views, opinions and conclusions expressed in this research article are views, opinions and conclusions of the author(s). Open Access Publishing Group and European Journal of Open Education and E-learning Studies shall not be responsible or answerable for any loss, damage or liability caused in relation to/arising out of conflict of interests, copyright violations and inappropriate or inaccurate use of any kind content related or integrated on the research work. All the published works are meeting the Open Access Publishing requirements and can be freely accessed, shared, modified, distributed and used in educational, commercial and non-commercial purposes under a Creative Commons Attribution 4.0 International License (CC BY 4.0). 